\title{
A real world experience with fingolimod in active RRMS patients naïve to second-line agents: a 2 years, intention-to-treat, observational, single center study
}

\author{
D. Baroncini ${ }^{1,2^{*}}$, M. Zaffaroni ${ }^{2}$, P. O. Annovazzi ${ }^{2}$, S. Baldini ${ }^{2}$ A. Bianchi², G. Minonzio ${ }^{3}$, G. Comi ${ }^{1}$ and A. Ghezzi ${ }^{2}$
}

\begin{abstract}
Background: Fingolimod is approved by EMA as a second-line treatment for relapsing-remitting multiple sclerosis (RRMS). Experience with fingolimod in real life is still limited. Aim of our study was to report data on fingolimod effectiveness in a real life cohort of Italian active RRMS patients, naïve to second-line agents, followed for 2 years. Fingolimod was a part of the patients' regular treatment and is produced by Novartis.

Methods: We included all consecutive RRMS patients starting fingolimod at our center according to EMA criteria before January 1st 2013. Exclusion criteria were a previous treatment with natalizumab or an immunosuppressant therapy in the previous 12 months. All patients were clinically evaluated quarterly, and performed brain MRI yearly. Definition of "no evidence of disease activity" (NEDA-3): no relapses, no brain MRI activity and no 6-months confirmed worsening in EDSS score.

Results: We included 38 RRMS patients, 35 switched from first-line injectable therapies. Six patients were also previously treated with immunosuppressants ( 5 mitoxantrone, 1 cyclophosphamide). At $24^{\text {th }}$ month 34 patients continued fingolimod treatment. Main adverse events were infections (18\%), liver-enzymes elevation (8\%), and leukopenia (8\%). After 12 and 24 months 79 and $63 \%$ of patients were relapses-free. Fingolimod significantly reduced ARR compared to the previous year ( $0.3 \pm 0.6$ vs $1.2 \pm 0.5 ; p<0.001)$. After 12 and 24 months 63 and $37 \%$ of patients had NEDA-3. Previous use of immunosuppressants and an ARR $\geq 1$ in the 2 years predicted disease activity.
\end{abstract}

Conclusion: Fingolimod significantly reduce disease activity in active RRMS patients, with no severe/ unexpected safety issues. Patients previously treated with immunosuppressants and with a higher ARR at baseline may respond less to fingolimod treatment.

\section{Background}

Fingolimod (FTY) is the first oral disease-modifying drug (DMD) approved for the treatment of relapsing remitting multiple sclerosis (RRMS). By acting as a functional antagonist on sphingosine-1-phosphate receptor, FTY blocks the capacity of lymphocytes to egress from lymph nodes, reducing their infiltration into the central

\footnotetext{
*Correspondence: damianobaroncini@gmail.com

'Department of Neurology, Institute of Experimental Neurology, Division of Neuroscience, San Raffaele Hospital, Milan, Italy

${ }^{2}$ Multiple Sclerosis Study Center, Sant'Antonio Abate Hospital, Via Eusebio

Pastori 4, Gallarate, Italy

Full list of author information is available at the end of the article
}

nervous system (CNS) [1]. Once daily FTY $0.5 \mathrm{mg}$ has demonstrated superior efficacy in reducing disease activity with respect to placebo $[2,3]$ and to intramuscular interferon (IFN) $\beta$-1a once/week [4] in randomized clinical trials (RCTs). Main adverse events (AEs) associated with FTY are herpes virus infections, first-dose induced bradycardia, arterial hypertension, macular edema, liverenzymes elevation, and lymphopenia [2-4].

The European Medicines Agency (EMA) approved FTY as a second-line treatment for patients with high disease activity despite treatment with first-line injectables DMDs (i.e. interferons and glatiramer acetate) 
or with a rapidly evolving course in patients naïve to DMDs [5].

FTY confirmed its safety and efficacy also in RCTs extension studies [6-8] and in different subgroups of patients [9]. However, drugs efficacy and safety need to be assessed outside the context of RCTs, in real world less selected populations. Until now only few studies have addressed this topic [10-12]. The aim of our study was therefore to better delineate the effectiveness and safety of FTY in a real life set.

\section{Objective}

To report data of a two years, observational, intentionto-treat (ITT) study of an Italian cohort of RRMS patients, naïve to second-line agents, who started FTY according to EMA prescription rules.

\section{Methods}

All consecutive RRMS patients starting FTY in our Center from July 2011 to January 1st 2013, according to EMA criteria were included. Patients should be naïve to second-line treatments (i.e. natalizumab or FTY), while a past therapy with immunosuppressants was allowed if finished at least 12 months before.

Patients were clinically evaluated (neurological examination and EDSS score assessment) 1 month after FTY initiation, then quarterly, recording AEs and relapses if occurred. Brain MRI scans were done in our center at baseline and then performed yearly for all patients. Blood exams (complete blood count, bilirubin, AST, ALT, GGT and creatinine) were performed after 1 month, then every 3 months.

Definition of "no evidence of disease activity" (NEDA-3): no relapses, no brain MRI activity ( $\geq 1$ new/enlarged T2 and/or $\geq 1$ gadolinium-enhancing lesion) and no worsening in EDSS score of at least $\geq 1$ point confirmed after 6 months ( $\geq 1.5$ points if $\mathrm{EDSS}=0 ; \geq 0.5$ points if $\mathrm{EDSS} \geq 5.5$ ).

An ITT analysis was performed, including patients who discontinued the treatment before the 24 months observation period. To determine whether there was a significant difference between the average values of the same variables pre and post-FTY a repeated measure ANOVA test and post-hoc Paired Sample $t$-test with Bonferroni correction was used. Time to first relapse and time to first evidence of disease activity (according to NEDA-3 definition) were evaluated using KaplanMeier analysis and curves.

For the determination of predictors of disease activity (according to NEDA-3) and relapses occurrences a multivariate proportional hazards model was applied with the following variables included: gender, previous immunosuppressants use, previous DMDs type (none, IFNs, Glatiramer Acetate, both), last DMD, DMDs therapy duration (years), washout period duration between
DMDs and FTY (months), MS duration (years), age at FTY initiation (years), presence/absence of activity in baseline brain MRI, EDSS score at baseline $(<3$ or $\geq 3)$, annualized relapse rate (ARR) in the 2 years before FTY therapy $(<1$ or $\geq 1)$. Hazard ratios (HR) and relative $95 \%$ confidence intervals (CI $95 \%$ ) were calculated.

A significance level of 0.05 was used for each test. For all the analysis, Wizard statistics for MAC (version 1.7.0) was used.

This study was approved by Comitato Etico Provinciale di Varese. Consent was obtained from the patients.

\section{Results}

Baseline clinical and demographic characteristics of our cohort are showed in Table 1 . A total of 38 patients were included: 35 were switched from first-line injectable DMDs and 3 were treatment naïve. Six patients switched from first-line DMDs were also previously treated with an immunosuppressant drug (Table 1). Seventeen patients received FTY before its commercial availability, being enrolled in the Expanded Access Program (CFT720DIT03). All patients presented clinical activity, and most of them also radiological activity (20/38) in the year before FTY initiation. The entire cohort was followed for 24 months.

A total of 4 patients $(10.5 \%)$ discontinued the treatment because of lack of efficacy (high number of relapses/disability progression, $n=2$ ), AEs (frequent cold and flu, $n=1)$ and pregnancy planning $(n=1)$. Mean time to treatment discontinuation was $16.4 \pm 1.7$ months. First-dose induced bradycardia was transient and asymptomatic for all patients. The lymphocyte count lowered during FTY treatment $\left(<1000\right.$ cells $\left./ \mathrm{mm}^{3}\right)$, but remained above the safe limits $\left(>200\right.$ cells $\left./ \mathrm{mm}^{3}\right)$. AEs were transient liver-enzymes elevation $(x 3$ the upper limit of normal range) in 3 patients, transient leukopenia (total

Table 1 Baseline clinical and demographic characteristics

\begin{tabular}{ll}
\hline & Cohort (38 patients) \\
\hline Gender (male/female) & $9 / 29$ \\
Age (y), mean \pm SD (range) & $39.6 \pm 7.3(26-53)$ \\
Disease duration (y), mean \pm SD (range) & $12.0 \pm 7.1(2-31)$ \\
EDSS score, median (range) & $2.0(0-6)$ \\
Previous ARR (1y/2y before), mean \pm SD & $1.2 \pm 0.5 / 0.8 \pm 0.4$ \\
Previous use of ISs (yes/no) & $6 / 32$ \\
Type of ISs (MTX/CTX) & $5 / 1$ \\
Time from ISs suspension (y), mean \pm SD (range) & $7.2 \pm 2.1$ (4-10) \\
Previous use of DMDs (yes/no) & $35 / 3$ \\
Type of DMDs (IFNs/GA/both) & $17 / 5 / 13$ \\
DMDs therapy duration (y), mean \pm SD (range) & $5.3 \pm 3.9$ (0.6-15) \\
\hline Legend: $y$ year, SD standard deviation, ARR annual relapse rate, \\
ISs immunosuppressants, MTX mitoxantrone, CTX cyclophosphamide, \\
$\begin{array}{l}\text { DMDs first-line disease modyfing drugs, IFNs interferons, GA glatiramer acetate, } \\
m \text { months, FTY fingolimod }\end{array}$
\end{tabular}


a)

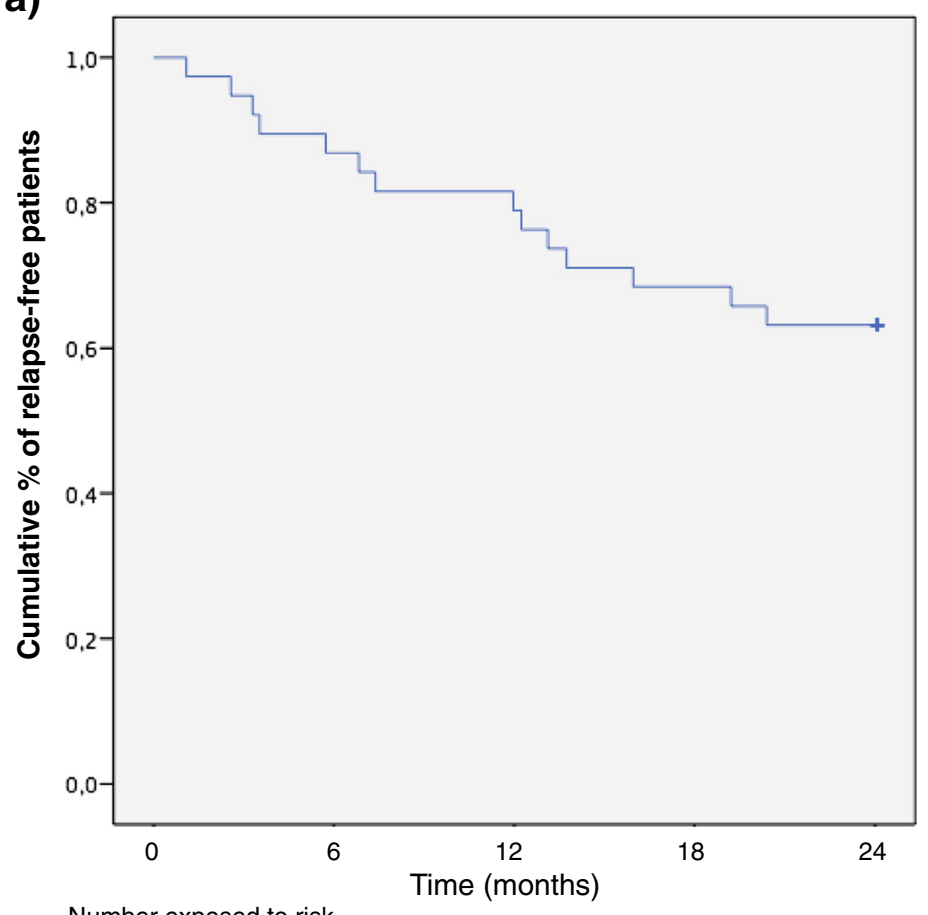

Number exposed to risk

38

$33 \quad 30$

26

24

b)



Fig. 1 Kaplan-Meier estimate for the time to relapse (a) and time to disease activity (failure to achieve NEDA-3 status) (b). In $\mathbf{b}$, the curve drop at 12 months is mainly related to detection of disease activity by brain MRI scans 
white blood cell count $<2500$ cells $/ \mathrm{mm}^{3}$ ) in 3 , infections in 7 (oral or genital herpes, $n=2$; otitits, $n=2$; flu and cold, $n=2$; candidal vulvovaginitis, $n=1$ ), palpitation in 2 , dizziness in 2 , headache in 1 and itchy skin in 1 . In one patient a severe AE occurred (acute pyelonephritis in chronic neurologic bladder disorder, fully recovered with antibiotics).

FTY markedly reduced ARR, which was $0.32 \pm 0.74$ and $0.34 \pm 0.71$ in the first and second year, significantly lower than ARR of 1 and 2 years before $(p<0.01$, see Table 1). Moreover, ARR reduction was sustained in the whole period of observation $(0.38 \pm 0.65)$, with respect to the previous 2 years $(p<0.001)$.

Eight patients (21\%) had a 6-months confirmed EDSS score worsening of $\geq 1$ point. Figure 1 shows the KaplanMeier estimate for the time-to-relapse and the time todisease-activity (according to NEDA-3 definition) over 24 months of follow-up.

Predictors of relapses occurrence were an ARR $\geq 1$ in the previous 2 years $(p=0.012$; HR 4.7, CI 1.1-21.0) and disease duration $(p=0.014$; HR 1.05, CI 1.03-1.30). Predictors of disease activity (according to NEDA-3 definition) were past use of immunosuppressants $(p=0.016$; HR 8.3, CI 1.5-47.0), ARR $\geq 1$ in the previous 2 years $(p=0.005$; HR 5.4, CI 1.7-17.4) and DMDs therapy duration ( $p=0.009$; HR 0.98, CI 0.97-0.99).

\section{Discussion}

Results of FTY therapy in this real-life experience were reassuring, showing a good safety profile. The majority of patients (90.5\%) remained on FTY treatment after 2 years. Main AEs were mild infections (18\%), liverenzymes elevation ( $8 \%$ ) and leukopenia (8\%). Considering the small sample size, AEs frequency was substantially within the range of those reported in RCTs [2-4] and in extension studies [6-8], without unexpected AEs.

FTY treatment significantly reduced ARR and the benefits were sustained: after 12 and 24 months of observation 79 and $63 \%$ of patients were relapses-free (Fig. 1). Considering a more restrictive criterion, 63 and $37 \%$ of patients presented NEDA-3 at 12th and 24th month. Our results about disability progression and percentage of relapsesfree patients are substantially in agreement with those of RCTs [2-4] and post-marketing observational studies $[6-8,10-12]$. Data from a post-hoc analysis of TRANSFORMS showed that $46 \%$ MS patients receiving FTY reached NEDA-3 status after 12 months [13]. In our cohort a higher percentage of patients were "disease-free" after 1 year: a smaller sample size, a more rigorous reading protocol of brain MRI scans and difference in definition of NEDA-3 (EDSS worsening was confirmed after 3 months in TRANSFORMS study, after 6 months in ours) could explain this difference. To our knowledge no data regarding NEDA-3 status after 2 years of FTY treatment has been reported at the time of paper submission.

A significant predictor of disease activity and relapses occurrence was an ARR $\geq 1$ in the previous 2 years, in accordance with the trend found in a post-hoc subgroup analysis of the FREEDOM study [9]. A previous immunosuppressant therapy was also associated with further disease activity, probably because a more severe disease characterizes these patients. The other two predictors found by the multivariate models (disease duration and previous DMDs therapy duration) are statistically but probably not clinically significant, due to their low HR (1.05 and 0.98 respectively). All these findings must be taken with caution and need confirmation by prospective observational studies on larger populations.

\section{Conclusion}

After 2 years of FTY treatment about $40 \%$ of our population of active RRMS patients presented no evidence of disease activity. Patients with a higher ARR at baseline or previously treated with immunosuppressants could respond less to FTY treatment. There were no unexpected adverse events. In spite of the evident limitations (mainly small sample size), observational ITT studies like ours provide useful data on the use of new medications in real life and less selected populations.

\section{Competing interests}

Dr. Baroncini has no relevant disclosures for this paper. He received personal compensation from Almirall for creation of editorial publications and travel grants for participation to National and International Congresses from Genzyme.

Dr. Zaffaroni has served on scientific advisory boards for Teva, Medtronics, Aventis, Merck Serono and Novartis, and served as a consultant for Biogen Idec. Dr. Annovazzi received honoraria for speaking and travel grants from Biogen Idec, Teva, Genzyme, Novartis, Almirall and Wellspect healthcare.

Dr. Baldini reports no disclosures.

Dr. Bianchi reports no disclosures.

Dr. Minonzio reports no disclosures.

Prof. Giancarlo Comi received personal compensation from Bayer Schering, Serono Symposia International Foundation, Merck Serono International, TEVA Pharmaceutical Ind. Ltd, Sanof-Aventis and Biogen Idec for consulting services, received personal compensation from TEVA Pharmaceutical Industries Ltd, Sanofi-Aventis, Serono Symposia Int. Foundation, Biogen Dompè and Bayer Schering for speaking activities. TEVA Pharmaceutical Industries Ltd, SanofiAventis, Serono Symposia Int. Foundation, Biogen Dompé and Bayer Schering have provided prof. Comi for the costs of travelling and lodging related to speaking activities.

Dr. Ghezzi received honoraria for speaking from Genzyme, Biogen-Idec, Merck-Serono, Novartis, and Almirall, for consultancy from Merck-Serono, Novartis, Biogen-Idec, Genzyme, received support for participation to National and International Congresses from Biogen-ldec, Merck-Serono Novartis, Genzyme, Teva.

\section{Authors' contributions}

$A G$ and $D B$ conceived the study. MZ, PA, DB, SB and AG performed neurological examinations and prospectively collected clinical and MRI data of all patients. GM performed brain MRI scan and participated in study coordination. $\mathrm{DB}$ and $\mathrm{AB}$ acquired data and created the database. DB drafted the manuscript, and performed the statistical analysis with external support. MZ, PA and SB participated in study design and its coordination. AG and GC reviewed the final version of the manuscript. All authors read and approved the final manuscript. 


\section{Acknowledgments}

Novartis International contributed by drafting a first version of the manuscript on input from authors, and giving statistical support.

\section{Funding}

Novartis supported article-processing charges. The authors had full editorial control of the manuscript, revised it critically in full intellectual autonomy, and provided their final approval of all contents.

\section{Author details}

'Department of Neurology, Institute of Experimental Neurology, Division of Neuroscience, San Raffaele Hospital, Milan, Italy. ${ }^{2}$ Multiple Sclerosis Study Center, Sant'Antonio Abate Hospital, Via Eusebio Pastori 4, Gallarate, Italy. ${ }^{3}$ Department of Neuroradiology, Sant'Antonio Abate Hospital, Via Eusebio Pastori 4, Gallarate, Italy.

\section{Received: 19 May 2015 Accepted: 17 February 2016}

\section{Published online: 01 April 2016}

\section{References}

1. Cohen JA, Chun J. Mechanisms of fingolimod's efficacy and adverse effects in multiple sclerosis. Ann Neurol. 2011;69:759-77.

2. Calabresi PA, Radue EW, Goodin D, et al. Safety and efficacy of fingolimod in patients with relapsing-remitting multiple sclerosis (FREEDOMS II): a double-blind, randomised, placebo-controlled, phase 3 trial. The Lancet Neurology. 2014:13:545-56.

3. Kappos L, Radue EW, O'Connor P, et al. A placebo-controlled trial of oral fingolimod in relapsing multiple sclerosis. N Engl J Med. 2010;362:387-401.

4. Cohen JA, Barkhof F, Comi G, et al. Oral fingolimod or intramuscular interferon for relapsing multiple sclerosis. N Engl J Med. 2010;362:402-15.

5. European Medicines Agency. Gilenya $0.5 \mathrm{mg}$ hard capsules; summary of product characteristics. http://www.ema.europa.eu/ema/index. jsp?curl=pages/medicines/human/medicines/002202/human_med_001433. jsp\&mid=WC0b01ac058001d124. Accessed 05 April 2015.

6. Kappos L, O'Connor P, Radue EW, et al. Long-term effects of fingolimod in multiple sclerosis: The randomized FREEDOMS extension trial. Neurology. 2015;84(15):1582-91.

7. Khatri B, Barkhof F, Comi G, et al. Comparison of fingolimod with interferon beta-1a in relapsing-remitting multiple sclerosis: a randomised extension of the TRANSFORMS study. The Lancet Neurology. 2011;10:520-9.

8. Cohen JA, Khatri B, Barkhof F, et al. Long-term (up to 4.5 years) treatment with fingolimod in multiple sclerosis: results from the extension of the randomised TRANSFORMS study. J Neurol Neurosurg Psychiatry. 2015;0:1-8. doi:10.1136/jnnp-2015-310597.

9. Devonshire V, Havrdova E, Radue EW, et al. Relapse and disability outcomes in patients with multiple sclerosis treated with fingolimod: subgroup analyses of the double-blind, randomised, placebo-controlled FREEDOMS study. The Lancet Neurology. 2012;11:420-8.

10. Al-Hashel J, Ahmed SF, Behbehani R, Alroughani R. Real-world use of fingolimod in patients with relapsing remitting multiple sclerosis: a retrospective study using the national multiple sclerosis registry in Kuwait. CNS Drugs. 2014;28:817-24.

11. Baldi E, Guareschi A, Vitetta F, et al. Previous treatment influences fingolimod efficacy in relapsing-remitting multiple sclerosis: results from an observational study. Curr Med Res Opin. 2014;30:1849-55.

12. Hersh CM, Hara-Cleaver C, Rudick RA, Cohen JA, Bermel RA and Ontaneda D. Experience with fingolimod in clinical practice. Int J Neurosci. 2014; 125(9):675-85. doi:10.3109/00207454.2014.969839.

13. 13. Khatri B, Barkhof F, Comi G, et al. Fingolimod treatment increases the proportion of patients who are free from disease activity in multiple sclerosis compared to IFN-B1A: Results from a phase 3, active-controlled study (TRANSFORMS). 64th American Academy of Neurology Annual Meeting; 2012; New Orleans (LO). Retrived from https://www.researchgate.net/ publication/270423169_Fingolimod_Treatment_Increases_the_Proportion_of_ Patients_Who_Are_Free_from_Disease_Activity_in_Multiple_Sclerosis Compared_to_IFN-bla_Results_from_a_Phase_3_Active-Controlled_Study_ TRANSFORMS_PD5006. Accessed 5 Apr 2015.

\section{Submit your next manuscript to BioMed Central and we will help you at every step:}

- We accept pre-submission inquiries

- Our selector tool helps you to find the most relevant journal

- We provide round the clock customer support

- Convenient online submission

- Thorough peer review

- Inclusion in PubMed and all major indexing services

- Maximum visibility for your research

Submit your manuscript at www.biomedcentral.com/submit
Biomed Central 